\title{
Estimativas de parâmetros genéticos e correlações entre caracteres fenológicos e morfoagronômicos em feijão-caupi
}

\author{
Agenor Martinho Correa ${ }^{1}$, Gessi Ceccon ${ }^{2}$, César Murilo de Albuquerque Correa ${ }^{3}$, Donato Spagnoli Delben ${ }^{3}$
}

\section{RESUMO}

Mensurar a variabilidade genética e conhecer as correlações entre caracteres de interesse para seleção numa população constitui uma das etapas iniciais em um programa de melhoramento genético. Com o objetivo de avaliar o potencial para o melhoramento genético de uma população composta por 19 genótipos de feijão-caupi de porte ereto e semiereto, entre variedades comerciais e linhagens avançadas, foram estimados parâmetros genéticos e fenotípicos e correlações entre caracteres fenológicos e morfoagronômicos da população. O experimento foi conduzido na área experimental da Universidade Estadual de Mato Grosso do Sul, em Aquidauana, no período da seca do ano agrícola 2007/2008. Foram avaliados os caracteres: dias para o florescimento (DF), dias para a maturação (DM), massa de 100 grãos (MCG), comprimento de vagem (CV), massa de vagem (MV), número de grãos por vagem (NGV) e produtividade de grãos secos (PROD). Verificou-se efeito significativo de genótipos para todas as características indicando existência de variabilidade. O maior valor da estimativa do coeficiente de variação genética foi obtido para PROD, que também apresentou o mais alto valor de coeficiente b, 2,05, indicando condição favorável para seleção desse caráter. Dentre os demais caracteres apenas para DM o valor do coeficiente $b$ foi superior a um. Foram observadas correlações genéticas positivas e significativas entre todos os caracteres e PROD, sendo as mais elevadas com DF, MV e NGV. Concluiu-se que a população apresentou potencial para o melhoramento genético e que aumento da produtividade de grãos pode ser obtido principalmente para genótipos mais tardios.

Palavras-chave: Vigna unguiculata (L.) Walp, parâmetros fenotípicos, variabilidade genética.

\section{ABSTRACT}

\section{Estimates of genetic parameters and correlations between phenological and morphological traits in cowpea}

Determining the genetic variability and correlations between traits of interest for selection in a population is one of the stages in a breeding program. The objectives of this study was to evaluate the potential for genetic improvement of a population composed of 19 cowpea genotypes of erect and semi-erect growth habits, involving commercial varieties and advanced lines. Genetic and phenotypic parameters and correlations between phenological and morphological traits of the population were estimated. The trial was carried out at the experimental field at the Universidade Estadual de Mato Grosso do Sul, in Aquidauana, in the dry season of the crop year 2007/2008. The following traits were evaluated: days to flowering (DF), days to maturity (DM), mass of 100 beans (MHB), length of pod (LP), mass of pods (MP), number of seeds per pod (NS) and dry bean yield (DBY). There was a significant effect

\footnotetext{
Recebido para publicação em 20/10/2010 e aprovado em 06/12/2011

${ }^{1}$ Engenheiro-agrônomo, Doutor. Universidade Estadual de Mato Grosso do Sul - UEMS, Rodovia Aquidauana - CERA, Km 12, Caixa Postal 25, 79200-000, Aquidauana, Mato Grosso do Sul, Brasil. agenor@uems.br.

${ }^{2}$ Engenheiro-agrônomo, Doutor. Embrapa Agropecuária Oeste, Rodovia BR 163, Km 253, 6, Caixa Postal 661, 79804-970, Dourados, Mato Grosso do Sul, Brasil. gessi@cpao.embrapa.br

${ }^{3}$ Graduando do curso de Agronomia da Universidade Estadual do Mato Grosso do Sul - UEMS. Rodovia Aquidauana - CERA, Km 12, Caixa Postal 25, 79200-000, Aquidauana, Mato Grosso do Sul, Brasil. cesar.lilo@hotmail.com, godines_o_grande@hotmail.com
}

Rev. Ceres, Viçosa, v. 59, n.1, p. 88-94, jan/fev, 2012 
of genotypes on all traits, indicating the existence of variability. The highest estimate of the genetic variation coefficient was obtained for DBY which also had the highest coefficient $b$ (2.05), indicating favorable condition for the selection of this trait. Among the other traits only DM had coefficient $b$ above one. There were positive and significant genetic correlations between all the traits and DBY; however, the highest were DF, MP and NS. These findings showed that this population has the potential for genetic improvement and the increase in bean yield can be obtained especially for the later genotypes.

Key words: Vigna unguiculata (L.) Walp, phenotypic parameters, genetic variability.

\section{INTRODUÇÃO}

O feijão-caupi (Vigna unguiculata (L.) Walp.), também conhecido como feijão-de-corda, feijão-macassar ou feijão-fradinho, é de grande importância para a economia das regiões Norte e Nordeste do Brasil e de amplo significado social, por se constituir no principal alimento proteico e energético da população rural. Suas sementes são fontes de proteínas e aminoácidos indispensáveis, como a tiamina e a niacina, além de fibras dietéticas, sendo consumidas na forma de grãos maduros e de grãos verdes, bastante apreciados por seu gosto e cozimento fácil, utilizados em pratos típicos da região nordestina (Ferreira \& Silva, 1987; Oliveira \& Carvalho, 1988; Silva \& Oliveira, 1993).

A espécie apresenta genótipos com ampla rusticidade e adaptabilidade às condições de estiagem prolongada e capacidade de se desenvolver em solos de baixa fertilidade, constituindo-se alternativa de baixo risco ao cultivo de grãos nas regiões risco climático para o feijão-comum (Phaseolus vulgaris L.) é elevado. (Oliveira \& Carvalho, 1988; Freire Filho et al., 2005a).

O feijão-caupi apresenta ampla variabilidade genética para praticamente todos os caracteres de interesse agronômico (Santos et al., 1997) e, de acordo com Freire Filho et al., (2005b), os objetivos do melhoramento do feijãocaupi, a curto e médio prazos, podem ser resumidos nos seguintes itens: aumento da produtividade e melhoria da qualidade visual, culinária e nutricional dos grãos; adaptabilidade e estabilidade da produção e tolerância a estresses hídricos; arquitetura de planta adequada a diferentes sistemas de cultivo mecanizado ou tradicional; incorporação de resistência múltipla às doenças; e desenvolvimento de grãos com características favoráveis ao processamento industrial, como cor verde persistente à secagem para o enlatamento e congelamento.

A quantificação das variabilidades fenotípica e genética presente em uma população é de fundamental importância para o desenvolvimento dos programas de melhoramento genético, porque permite conhecer o controle genético do caráter e o potencial da população para seleção (Ramalho et al., 2000). A determinação do controle genético dos caracteres que são objetivos da seleção constitui uma etapa inicial que orienta a escolha dos procedimentos mais adequados nos programas de melhoramento (Santos et al.,1985).

$\mathrm{O}$ estudo do controle genético e da herança de caracteres agronômicos por meio da obtenção de estimativas de parâmetros genéticos como Variâncias, Herdabilidade, Coeficiente de determinação genotípico, Coeficiente de variação genética e Coeficiente $b(\mathrm{CVg} / \mathrm{CVe})$ de uma população que se pretende explorar para o melhoramento genético permite fazer inferências sobre a variabilidade genética que esta apresenta e o que pode se esperar de ganho com seleção. As estimativas obtidas são usadas pelo melhorista para definir as melhores estratégias de seleção para a obtenção de genótipos superiores (Correa et al., 2003).

Estimativas de parâmetros genéticos do feijão-caupi têm sido obtidas por vários autores (Santos \& Santos, 2004; Matos Filho et. al., 2009; Benvindo et al., 2010), e essas têm contribuído para aumentar a eficiência dos programas de melhoramento genético da espécie (Shing, 2007). Diante da enorme variabilidade genética apresentada pela espécie e da grande variação nas condições de seu cultivo, essas estimativas são primordiais para o estabelecimento de programas de melhoramento com o objetivo de desenvolver cultivares mais produtivos e adaptados a essas diferentes condições.

Quando se explora a variabilidade por meio da seleção sobre determinado caráter, outros caracteres podem ser simultaneamente alterados, devido à correlação genética entre os caracteres (Santos \& Vencovsky, 1986). As correlações são explicadas por dois fatores: a ligação física de genes que estão no mesmo cromossomo e que afetam diferentes características e pelo efeito de um mesmo gene em mais de uma característica (pleiotropia). Deve-se conhecer e quantificar essas correlações para que se possa prever o efeito da seleção em todos os caracteres de interesse.

Este estudo teve como objetivo estimar parâmetros genéticos e correlações entre caracteres de interesse agronômico em uma população de feijão-caupi. 


\section{MATERIAL E MÉTODOS}

O experimento foi conduzido na área experimental da Unidade de Aquidauana da Universidade Estadual de Mato Grosso do Sul, localizada nas coordenadas $22^{\circ} 20^{\prime} 00^{\prime \prime}$ latitude Sul e 55 48' 00" longitude Oeste, com altitude de 207 metros. O clima da região, segundo Koppen, é classificado como Tropical Quente e Subúmido - AW, com precipitações pluviométricas médias anuais de 1.200 a 1.300 mm e temperatura média anual de $24^{\circ} \mathrm{C}$ (Estado de Mato Grosso do Sul, 1990).

O solo é classificado como Argissolo Vermelho-Amarelo distrófico, com textura arenosa e média a alta fertilidade natural. O experimento foi realizado no período da seca do ano agrícola 2007/2008.

Foram avaliados 19 genótipos (Tabela 1) procedentes do Banco de Germoplasma da Embrapa Meio Norte, Teresina, PI, sendo 15 linhagens avançadas e quatro cultivares. $\mathrm{O}$ experimento foi instalado seguindo o delineamento experimental blocos inteiramente casualizados, com quatro repetições. As unidades experimentais constaram de quatro fileiras de plantas com 5,0 m de comprimento cada, espaçadas de 0,50 m entre si, deixando-se, após desbaste, oito plântulas por metro linear. Como área útil foi considerada apenas as duas linhas centrais de cada parcela, onde se processaram as avaliações.

O preparo da área, a semeadura e o manejo da cultura seguiram as recomendações técnicas para a espécie (Freire Filho et al., 2005a). A semeadura foi realizada em 12/04/ 2008, e a colheita foi concluída no dia 11 de julho, 90 dias após a semeadura, quando as vagens já se encontravam secas.

Tabela 1. Genótipos utilizados no experimento

\begin{tabular}{lc}
\hline Genótipos & Variedade/Linhagem \\
\hline MNC99-537F-1 & Linhagem \\
MNC99-541F-5 & Linhagem \\
MNC99-541F-8 & Linhagem \\
MNC99-542F-5 & Linhagem \\
BRS Nova Era & Variedade \\
MNCOO-553D-8-1-2-3 & Linhagem \\
MNC99-557F-2 & Linhagem \\
MNCO1-627F-14-2 & Linhagem \\
MNCO1-627F-14-5 & Linhagem \\
MNCO3-720C-20 & Linhagem \\
MNCO3-720C-31 & Linhagem \\
MNCO3-731C-21 & Linhagem \\
MNCO3-732C-5 & Linhagem \\
TvX-5058-09C & Linhagem \\
MNCO5-784B-38-2 & Linhagem \\
MNCO5-823B-234-5 & Linhagem \\
Viana-Blanca & Variedade \\
Califórnia Blackeye-27 & Variedade \\
BRS Guariba & Variedade \\
\hline
\end{tabular}

Em cada parcela foram avaliados os seguintes caracteres:

a) dias para o florescimento (DF): período, em dias, entre a semeadura e a abertura da primeira flor;

b) dias para a maturação (DM): período, em dias, entre a semeadura e o surgimento da primeira vagem de coloração modificada;

c) massa de 100 grãos (MCG): em gramas, corrigida para $13 \%$ de umidade, verificada utilizando-se balança eletrônica semianalítica com precisão de duas casas decimais;

d) comprimento de vagem (CV): em centímetros, quando as vagens mudaram de cor (início da maturação), sendo medidas cinco vagens coletadas aleatoriamente nas plantas da área útil da parcela;

e) massa de vagem verde (MV): em gramas, utilizando as cinco vagens coletadas para mensuração do comprimento, pesadas em balança eletrônica, semianalítica, com precisão de duas casas decimais;

f) número de grãos por vagem (NGV): média de cinco vagens, sendo o número de grãos contado manualmente, utilizando-se as vagens amostradas para comprimento e massa; e

g) produtividade de grãos secos (PROD): estimada considerando-se a produção colhida na área útil da parcela $\left(\mathrm{m}^{2}\right)$, extrapolando-se o valor obtido para $\mathrm{kg} \mathrm{ha}^{-1} \mathrm{com}$ correção da massa dos grãos para $13 \%$ de umidade.

$\mathrm{Na}$ análise dos resultados foi utilizada a análise de variância, adotando-se o seguinte modelo estatístico (Cruz et al., 2004): $Y_{i j}=\mu+g_{i}+b_{j}+\varepsilon_{i j}$, em que:

$Y_{i j}=$ valor da característica do $i$-ésimo genótipo no j-ésimo bloco;

$\mu=$ média geral do ensaio;

$g_{i}=$ efeito do $i$-ésimo genótipo $(i=1,2, \ldots, g)$;

$b_{j}=$ efeito do $j$-ésimo bloco $(j=1,2 \ldots, r)$; e

$\varepsilon_{i j}=$ erro aleatório associado ao genótipo $i$ e ao bloco $j \varepsilon_{i j}$ $\sim \operatorname{NID}\left(0, \sigma^{2}\right)$.

Os parâmetros genéticos e seus estimadores foram analisados para cada característica, utilizando-se as seguintes expressões (Cruz et al., 2004):

a) Variância fenotípica: $\left(S^{2} F\right)=Q M_{g} / k$

b) Variância ambiental média: $\left(S^{2} E\right)=Q M_{r} / k$

c) Variância genotípica média; $\left(\hat{\sigma}_{g}^{2}\right)=\left(Q M_{g}-Q M_{r}\right) / k$

d) Coeficiente de determinação genotípico: $R^{2}=\hat{\sigma}_{G} / \hat{\sigma}_{F}$

e) Coeficiente de variação genético: $\left(C V_{g}\right)=\frac{\sqrt{\hat{\sigma}^{2}}}{m} x 100$

f) Coeficiente de variação experimental: $C V_{e}=100\left(\sqrt{Q M_{e}} / \mathrm{m}\right)$

Rev. Ceres, Viçosa, v. 59, n.1, p. 88-94, jan/fev, 2012 
g) Quociente $b:\left(C V_{g} / C V_{e}\right)=\sqrt{\frac{\hat{\sigma}_{G}^{2}}{\hat{\sigma}^{2}}}$

em que: $\mathrm{k}=\frac{N-\left(\frac{1}{N} \sum_{i=1}^{g} r_{i}\right)}{g-1}$ e $\mathrm{N}=\sum_{i=1}^{g} r_{i}$, em que $r_{i}$ é o nú-

mero máximo de repetição do $i$-ésimo genótipo.

Nas estimativas das correlações empregaram-se as expressões citadas por Falconer (1987) e Ramalho et al.(1993):
a) Correlação fenotípica $\left(r_{F}\right) r_{F(c y)}=\frac{C O V_{F(x y)}}{\sqrt{\sigma_{F x . . \sigma_{F y}^{2}}^{2}}}$
b) Correlação genotípica $\left(r_{g}\right) r_{G(x y)}=\frac{C O V_{G(x y)}}{\sqrt{\sigma^{2}{ }_{G x} \sigma_{G y}^{2}}}$
c) Correlação ambiental $\left(r_{E}\right)\left(r_{E}\right)=\frac{C O V_{E(x y)}}{\sqrt{\sigma_{E x}^{2} \cdot \sigma^{2} E y}}$

em que: $r_{x y}$ correlação entre os caracteres X e Y; $C O V_{x y}=$ covariância entre os caracteres X e Y; e $\sigma_{x}^{2}$ e $\sigma_{y}^{2}=$ variância dos caracteres $\mathrm{X}$ e $\mathrm{Y}$, respectivamente.

As estimativas dos componentes de variância e parâmetros genéticos e fenotípicos foram obtidas utilizando-se o aplicativo computacional GENES (Cruz, 2006).

\section{RESULTADOS E DISCUSSÃO}

Na Tabela 2 é apresentado o resumo das análises de variância e as estimativas dos parâmetros genéticos. Os resultados evidenciaram a existência de ampla variabilidade genética na população, sendo verificados efeitos significativos $(\mathrm{p}<0,01)$ de tratamentos na análise de variância de todos os caracteres avaliados. Considerando-se que a existência da variabilidade genética numa população é fator determinante para qualquer programa de melhoramento (Ramalho et al., 2000), o germoplasma em estudo mostra-se, a princípio, promissor para trabalhos de seleção ou hibridações com potencial para o desenvolvimento de novos cultivares.

$\mathrm{O}$ coeficiente de variação genotípico $\left(\mathrm{CV}_{\mathrm{g}}\right)$ variou de 2,42 (DF) a 31,49\% (PROD) (Tabela 2). A estimativa de $31,49 \%$ para o caráter PROD é considerada alta (Correa $e t$ al., 2003) e indica que entre todos os caracteres estudados ele é o que mostra maior variabilidade, sendo altamente promissor para a realização da seleção. Ubi et al. (2007) encontraram para os caracteres "massa de 100 grãos" e "comprimento de vagem" coeficientes de variação genética de 9,2 e 25,9\%, respectivamente, sendo o primeiro menor e o segundo maior do que as estimativas obtidas neste trabalho. Para o caráter PROD o $\mathrm{CV}_{\mathrm{g}}$ estimado foi superior ao obtido por Lopes et al. (2001), de 26\%; Matos Filho et al. (2009), de 23\%; e Benvindo et al. (2010), de $15,05 \%$, assemelhando-se ao de Andrade et al. (2010), de $31,62 \%$.

As mais baixas estimativas de $\mathrm{CV}_{\mathrm{g}}$ foram para os caracteres DF (2,42\%), DM (3,75\%) e MCG (6,37\%). Benvindo et al. (2010) também obtiveram para o caráter "dias para a floração" baixa estimativa de $\mathrm{CV}_{\mathrm{g}}(1,62 \%)$, evidenciando possíveis dificuldades na seleção para este caráter.

Tabela 2. Resumos das análises de variância e estimativas de parâmetros genéticos para caracteres de genótipos de feijão-caupi de porte ereto e semiereto

\begin{tabular}{lccccrrr}
\hline F.V. & DF & DM & MCG & CV & MV & NGV & PROD \\
\hline Genótipo $(G L=18)$ & $14,47^{* *}$ & $31,01^{* *}$ & $52,26^{* *}$ & $5,39 * *$ & $16,08^{* *}$ & $176,94 * *$ & $728201,42 * *$ \\
Resíduo $(\mathrm{GL}=54)$ & 1,65 & 3,16 & 14,98 & 1,15 & 3,41 & 41,75 & 40701,08 \\
Média & 45,32 & 70,29 & 23,09 & 16,17 & 12,91 & 42,06 & 1317,04 \\
CV $(\%)$ & 2,83 & 2,53 & 16,76 & 6,63 & 14,31 & 15,36 & 15,32 \\
\hline \multicolumn{7}{c}{ Parâmetros genéticos } \\
\hline$\sigma_{F}^{2}$ & 1,62 & 7,75 & 13,06 & 1,35 & 4,01 & 44,23 & 182050,36 \\
$\sigma_{G}^{2}$ & 1,21 & 6,96 & 9,32 & 1,06 & 3,17 & 33,80 & 171875,09 \\
$\sigma_{E}^{2}$ & 0,41 & 0,79 & 3,74 & 0,29 & 0,84 & 10,43 & 10175,27 \\
$R^{2}$ & 75,01 & 89,80 & 71,33 & 78,72 & 78,76 & 76,41 & 94,41 \\
$C V_{g}(\%)$ & 2,42 & 3,75 & 13,21 & 6,37 & 13,78 & 13,82 & 31,49 \\
$b\left(C V_{g} / C V_{e}\right)$ & 0,86 & 1,48 & 0,79 & 0,96 & 0,96 & 0,90 & 2,05 \\
\hline
\end{tabular}

$\overline{\mathrm{F} . \mathrm{V}}=$ Fonte de Variação; DF = dias para o florescimento; DM = dias para a maturação; MCG = massa de 100 grãos; CV = comprimento de vagens $(\mathrm{cm}) ; \mathrm{MV}=$ massa de cinco vagem (grama), NGV = número de grãos em cinco vagem, PROD = produtividade de grãos secos $\left(\mathrm{kg} \mathrm{ha}^{-1}\right) . C V=$ coeficiente de variação; $\sigma_{F}^{2}=$ variância fenotípica; $\sigma^{2}{ }_{G}=$ variância genotípica; $\sigma_{E}^{2}=$ variância ambiental; $R^{2}=$ coeficiente de determinação genotípico; $C V_{g}=$ coeficiente de variação genotípico; $b=$ quociente $\mathrm{b}=\left(C V_{g} / C V_{e}\right)$; e $(* *)=\operatorname{significativo}$ a de $1 \%$ de probabilidade pelo teste $\mathrm{F}$. 
As estimavas de coeficiente de determinação genotípico $\left(R^{2}\right.$ - Tabela 2$)$ foram altas (acima de $75 \%$ ) para quase todos os caracteres avaliados, exceto para o MCG (71,33\%), evidenciando maiores dificuldades na seleção desse caráter, principalmente nas gerações com maior percentual de heterozigotos. A mais alta estimativa para o coeficiente de determinação genotípico foi para o caráter PROD $(94,41 \%)$.

Segundo Teixeira et al (2007), estimativas elevadas para $R^{2}$ podem ser devidas à variabilidade genética inerente aos genótipos testados, em razão de cada um deles contribuir com uma identidade genética distinta. Fehr (1987) menciona que coeficientes de determinação genotípico mais altos podem estar associados com a menor variação de ambiente e menor interação genótipos por ambiente. De acordo com Pimentel Gomes (1990), observa-se precisão de média a alta no controle ambiental, uma vez que os coeficientes de variação $(\mathrm{CV})$ foram abaixo de $20 \%$ para todos os caracteres (Tabela 2), variando de 2,53\% para o caráter "DF" a 16,76\% para o caráter MCG. Resultados semelhantes para os mesmos caracteres foram também obtidos por Torres et al. (2006) e Matos Filho et al. (2009).

Altas estimativas de $R^{2}$ para componentes de produção associadas a estimativas de correlações diretas e de alta magnitude com o caráter PROD podem indicar a pos- sibilidade de se fazer seleção indireta, via componentes de produção, para o aumento da produtividade de grãos. Os coeficientes de determinação genotípicos obtidos para os componentes da produção CV, NGV e MCG foram inferiores aos obtidos por Andrade et al. (2010), que obtiveram, para esses caracteres, respectivamente, 98,72, 96,98 e 94,80\%. Teixeira et al. (2007) encontraram para o caráter MCG $R^{2}$ de $92,81 \%$ superior ao obtido neste trabalho. Elevadas estimativas de $R^{2}$ para os componentes da produção foram também obtidas por Lopes et al. (2001) e Ubi et al. (2007).

Benvindo et al. (2010), avaliando genótipos de feijãocaupi de porte semiprostrado em cultivo de sequeiro e irrigado, estimaram para os caracteres "dias para a floração" e "produtividade de grãos secos" $R^{2}$ de $56,07 \%$ e $88,54 \%$, respectivamente valores inferiores aos obtidos neste trabalho. Matos Filho et al. (2009), avaliando o potencial de progênies de feijão-caupi com arquitetura ereta de planta, estimaram para o caráter "dias para a floração" coeficiente de determinação genotípico de 25,29\%, evidenciando forte presença dos efeitos de ambiente na expressão desse caráter nas condições em que o ensaio foi desenvolvido.

O quociente $b$ variou de 0,79 para o caráter MCG a 2,05 para PROD (Tabela 2), sendo superior a um apenas para os caracteres DM e PROD, indicando situações favoráveis à

Tabela 3. Estimativas de correlações $r_{F}, r_{G}$ e $r_{E}$ entre caracteres para genótipos de feijão-caupi de porte ereto e semiereto avaliados em Aquidauana-MS, 2008

\begin{tabular}{|c|c|c|c|c|c|c|c|}
\hline Caracteres & DF & DM & MCG & $\mathrm{CV}$ & MV & NGV & PROD \\
\hline$r_{F}$ & $1,00 * *$ & $0,50 * *$ & $-0,08^{\text {ns }}$ & $0,06^{\mathrm{ns}}$ & $0,29 *$ & $0,23 *$ & $0,43^{*}$ \\
\hline DF.... $r_{G}$ & $1,00 * *$ & $0,63 * *$ & $-0,14^{\mathrm{ns}}$ & $0,11^{\mathrm{ns}}$ & $0,34 *$ & $0,32 *$ & $0,54 * *$ \\
\hline$r_{E}$ & $1,00 * *$ & $-0,12^{\mathrm{ns}}$ & $0,07^{\mathrm{ns}}$ & $-0,09^{\text {ns }}$ & $0,12^{\mathrm{ns}}$ & $-0,06^{\mathrm{ns}}$ & $-0,10^{\mathrm{ns}}$ \\
\hline$r_{F}$ & & $1,00 * *$ & $-0,40^{*}$ & $-0,21^{*}$ & $-0,16^{\mathrm{ns}}$ & $0,05^{\mathrm{ns}}$ & $0,19^{*}$ \\
\hline DM... $r_{G}$ & & $1,00 * *$ & $-0,48^{*}$ & $-0,23^{*}$ & $-0,18^{\mathrm{ns}}$ & $0,07^{\mathrm{ns}}$ & $0,22 *$ \\
\hline$r_{E}$ & & $1,00 * *$ & $-0,07^{\mathrm{ns}}$ & $-0,08^{\text {ns }}$ & $-0,07^{\mathrm{ns}}$ & $-0,03^{\text {ns }}$ & $-0,19 *$ \\
\hline$r_{F}$ & & & $1,00 * *$ & $-0,12^{\mathrm{ns}}$ & $0,50 * *$ & $-010^{\mathrm{ns}}$ & $0,31^{*}$ \\
\hline MCG $r_{G}$ & & & $1,00 * *$ & $-0,08^{\text {ns }}$ & $0,54 * *$ & $-0,15^{\text {ns }}$ & $0,42 *$ \\
\hline$r_{E}$ & & & $1,00 * *$ & $-0,22^{*}$ & $0,38^{*}$ & $0,06^{\mathrm{ns}}$ & $-0,31 *$ \\
\hline$r_{F}$ & & & & $1,00 * *$ & $0,39 *$ & $0,55^{* *}$ & $0,31^{*}$ \\
\hline $\mathrm{CV} \ldots . r_{G}$ & & & & $1,00 * *$ & $0,39 *$ & $0,64 * *$ & $0,36^{*}$ \\
\hline$r_{E}$ & & & & $1,00 * *$ & $0,38^{*}$ & $0,22 *$ & $-0,03^{\text {ns }}$ \\
\hline$r_{F}$ & & & & & $1,00 * *$ & $0,37 *$ & $0,71 * *$ \\
\hline $\mathrm{MV} \ldots . . r_{G}$ & & & & & $1,00 * *$ & $0,34^{*}$ & $0,83 * *$ \\
\hline$r_{E}$ & & & & & $1,00 * *$ & $0,48 *$ & $-0,07^{\text {ns }}$ \\
\hline$r_{F}$ & & & & & & $1,00 * *$ & $0,56 * *$ \\
\hline NGV. $r_{G}$ & & & & & & $1,00 * *$ & $0,65 * *$ \\
\hline$r_{E}$ & & & & & & $1,00 * *$ & $0,10^{\mathrm{ns}}$ \\
\hline$r_{F}$ & & & & & & & $1,00 * *$ \\
\hline $\mathrm{PROD} r_{G}$ & & & & & & & $1,00 * *$ \\
\hline$r_{E}$ & & & & & & & $1,00 * *$ \\
\hline
\end{tabular}

$\overline{\mathrm{DF}}=$ dias para o florescimento; $\mathrm{DM}=$ dias para a maturação; $\mathrm{MCG}=$ massa de 100 grãos; $\mathrm{CV}=$ comprimento de vagens; $\mathrm{MV}=$ massa de cinco vagens; $\mathrm{NGV}=$ número de grãos em cinco vagens; PROD = produtividade de grãos secos $\left(\mathrm{kg}\right.$ ha $\left.{ }^{-1}\right)$; ${ }^{\text {ns }}=$ não significativo; e $*$, $* *$ $=$ significativos a 5 e a $1 \%$, respectivamente, pelo teste $\mathrm{t}$. 
seleção para esses caracteres de acordo com a interpretação deste valor recomendada por Vencovsky (1978).

Na Tabela 3 estão apresentadas as estimativas de correlações fenotípica $\left(r_{F}\right)$, genotípica $\left(r_{g}\right)$ e ambiental $\left(r_{E}\right)$ entre os caracteres avaliados. Observa-se que as estimativas indicam boa concordância dos sinais e de intensidade entre as correlações fenotípicas e genotípicas, apresentando as correlações genotípicas, no geral, valores superiores as suas correspondentes correlações ambientais e fenotípicas.

As mais altas correlações genotípicas e fenotípicas positivas e significativas foram entre os pares de caracteres MV x PROD; NGV x PROD; CV x NGV; MCG x $\mathrm{MV}$; e DF x DM, evidenciando, nos dois primeiros casos, que os caracteres MV e NGV são os componentes que mais contribuem para a produção de grãos do feijão-caupi, superando a MCG, e que a seleção de cultivares mais produtivos implicará em aumento da massa das vagens e do número de grãos por vagem. Andrade et al. (2010) também encontraram para os pares de caracteres CV x NGV e MV x MCG elevadas estimativas de correlações genotípica e fenotípica positivas.

Caracteres que definem o ciclo do feijão-caupi (DF e DM) correlacionam-se fenotípica e genotipicamente de forma positiva e significativa, embora de pequena intensidade, com a PROD, de forma que as cultivares de ciclo mais tardio tendem a ser mais produtivas, fato também observado por Machado et al. (2008), que encontraram estimativas de correlações positivas, significativas e de intensidades mais altas do que as verificadas neste trabalho entre os caracteres DF x PROD e DM x PROD.

Maior duração do período vegetativo (DF) proporciona aumentos na MV e no NGV, componentes que mais se correlacionam positivamente com a produção (PROD), todavia, prolongamento da subfase "florescimentomaturação" pouco influencia ou influencia de forma negativa os componentes MCG, CV e MV.

As mais altas correlações genotípicas e fenotípicas negativas se deram entre os caracteres DM x MCG, o que pode ser explicado pelo processo gradativo de desidratação dos grãos no campo após sua maturação fisiológica. De acordo com Falconer \& Mackay (1996), correlações genotípica e de ambiente de sinais trocados, como podem ser observadas em alguns pares de caracteres (Tabela 3), evidenciam que as causas de variação genética e de ambiente influenciaram os caracteres por meio de diferentes mecanismos fisiológicos.

\section{CONCLUSÕES}

A população apresenta variabilidade genética e potencial para o melhoramento genético, e ganho em produtividade de grãos pode ser obtido principalmente para genótipos mais tardios.

\section{REFERÊNCIAS}

Andrade FN; Rocha MM, Ferreira Gomes RL, Freire filho FR. \& Ramos SRR (2010). Estimativas de parâmetros genéticos em genótipos de feijão-caupi avaliados para feijão fresco. Revista Ciência Agronômica, 41:253-258.

Benvindo RN, Silva JAL, Freire Filho FR, Almeida ALG, Oliveira JTS. \& Bezerra AAC (2010) Avaliação de genótipos de feijãocaupi semi-prostrado em cultivo de sequeiro e irrigado. Comunicata Scientie, 1:23-28.

Correa AM, Gonçalves MC, Destro D \& Souza LCF \& Sobrinho TA. (2003) Estimates of genetic parameters in common bean genotypes. Crop Breeding and Applied Biotechonology, 3:223 -230 .

Cruz CD. (2006) Programa GENES: Biometria. Viçosa, Editora UFV. 382p.

Cruz CD, Regazzi AJ \& Carneiro PCS. (2004) Modelos biométricos aplicados ao Melhoramento Genético. $3^{\mathrm{a}}$ ed. Viçosa, Editora UFV. $585 \mathrm{p}$.

Estado de Mato Grosso do Sul. (1990) Atlas Multirreferencial. Campo Grande, Secretaria de Planejamento e Coordenação Geral. $28 \mathrm{p}$.

Falconer DS (1987) Introdução à genética quantitativa. Trad. Silva MA. \& Silva JC. Viçosa, Imprensa Universitária Federal de Viçosa. 279p.

Falconer DS \& Mackay TFC.(1996) Introduction to quantitative genetics. ${ }^{\mathrm{a}} \mathrm{ed}$. England,: Longman. 463p.

Fehr WR.(1987) Principles of cultivars development. New York:, Mac millan. 536p.

Ferreira JM \& Silva PSL. (1987) Produtividade de "feijão-verde" e outras características de cultivares de caupi. Pesquisa Agropecuária Brasileira, 1:55-58

Freire Filho FR, Araujo Lima JA \& Ribeiro VQ. (2005a) Feijãocaupi: Avanços tecnológicos. Brasília, EMBRAPA (Informação Tecnológica). 519p.

Freire Filho FR, Ribeiro VQ, Barreto PD \& Santos AA (2005b). Melhoramento Genético. In: Freire Filho, FR; Araujo Lima, JA \& Ribeiro VQ. (Eds.) Feijão-caupi: Avanços tecnológicos. Brasília, EMBRAPA (Informação Tecnológica). p.29-92.

Lopes AC, Freire Filho, F. R; Silva RQB, Campos FL. \& Rocha MM.(2001) Variabilidade e correlações entre caracteres agronômicos em caupi (Vigna unguiculata). Pesquisa Agropecuária Brasileira, 36:515-529.

Machado CF, Teixeira NJ, Freire Filho FR, Rocha MR, Gomes RL $\mathrm{F}$ (2008). Identificação de genótipos de feijão-caupi quanto à precocidade, arquitetura da planta e produtividade de grãos. Revista Ciência Agronômica, 39:114-123.

Matos Filho CHA, Gomes RLF, Rocha MM, Freire Filho FR \& Lopes ACA (2009) Potencial produtivo de progênies de feijão-caupi com arquitetura ereta de planta. Ciência Rural, 39:348-354.

Oliveira IP \& Carvalho AMA (1988) A cultura do caupi nas condições de clima e solo dos trópicos úmidos e semi-áridos do Brasil. In: Araujo JP; Watt, EA. (Eds.) O caupi no Brasil. Brasília, IITA/EMBRAPA. p.69-89.

Ramalho MAP, Santos JB \& Pinto CABP (2000). Genética na Agropecuária. $7^{\mathrm{a}}$ ed. São Paulo, Editora Globo. 359p.

Ramalho MAP, Santos JB \& Zimmermann, MJO (1993) Genética quantitativa em plantas autógamas: aplicação ao melhoramento do feijoeiro. Goiânia, UFG. 271p. 
Santos CAF, Menezes EA \&. Araujo FP (1997). . Divergência genética de feijão-de-corda avaliados em dois ambientes. Viçosa, 44:35-42.

Santos CAF \& Santos GM. (2004) Correlações fenotípicas em dois cruzamentos de feijão-caupi nas gerações $F_{2}, F_{3}, F_{4}$ e $F_{5}$. Horticultura Brasileira, Suplemento. 1 CD-ROM.

Santos JB \& Vencovsky R. (1986) Correlações fenotípicas e genética entre alguns caracteres agronômicos do feijoeiro (Phaseolus vulgaris L.). Ciência e Prática, 10:265-272.

Santos JB, Vencovsky R. \& Ramalho MAP(1985). Controle genético da produção de grãos e seus componentes primários em feijoeiro. Pesquisa Agropecuária Brasileira,. 20:1203-1211.

Shing BB.(2007) Recent progress in cowpea genetics and breeding. Acta Horticulture, 752:69-75.

Silva PSL \& Oliveira CN (1993). Rendimentos de feijão verde e maduro de cultivares de caupi. Horticultura Brasileira, 11: 133-135.
Teixeira NJP, Machado CF, Freire Filho FR, Rocha MM, Gomes RLF (2007) Produção, componentes de produção e suas interrelações em genótipos de feijão-caupi [ Vigna unguiculata (L.) Walp.] de porte ereto. Revista Ceres, 54:374-382.

Torres, FE, Sagrilo, E, Abreu, FB, Queiroz, LS, Moraes, SCFC, Damasceno, JE, Bertoncello, V \& Freire Filho, FR. (2006) Estimativas de parâmetros genéticos em linhagens de porte prostrado avaliadas em Aquidauana. In: Congresso Nacional de Feijão-Caupi, Teresina. Anais, Embrapa Meio Norte. Disponível em: <http://www.cpamn.embrapa.br/congressos/conac.2006/> Acessado em: 10 de setembro de 2011.

Ubi BE, Mignouna H. \& Obigbesan G.(2007) Segregation for seed wight, pod lenghts and days to flowering following a cowpea cross. African Crop Science Journal, 9:463-470.

Vencovsky R.(1978) Herança quantitativa. In: Patterniani E. (Coord) Melhoramento e produção de milho no Brasil. Piracicaba, Marprint. p.122-201. 